Thorax (1949), 4, 82.

\title{
EXCISION OF THE LUNG FOR PULMONARY TUBERCULOSIS
}

BY

\author{
T. HOLMES SELLORS AND M. D. HICKEY \\ From the London Chest Hospital
}

Until recently the fear of the effects of injury to tuberculous tissue has caused the surgeon to refrain from any procedure which would be accompanied by direct trauma of the actual lesions in the lung substance. The danger of exacerbation of the disease both locally and generally was a very real one, and many reports on the results of operations for bronchiectasis, for example, have shown that tuberculosis was a serious and often unexpected complication (Sellors et al., 1944). During the past few years, however, technical improvements and greater experience in the selection of patients have made it possible for deliberate excision of lung to be safely undertaken in certain cases of pulmonary tuberculosis.

In this article both inadvertent or "accidental " and deliberate instances of excision in the presence of pulmonary tuberculosis are discussed. The "accidental" excisions were performed on the supposition that the condition was straightforward bronchiectasis or a suspected neoplasm, and this category includes patients who were operated on any time up to 15 years ago. The deliberate resections have only been undertaken during the past three or four years and have been confined to cases in which other forms of therapy were considered unsuitable.

The long-term results in instances of accidental excision are well known, but those in cases of deliberate lobectomy or pneumonectomy have not been fully established. There is, of course, Macewen's classic case in which a tuberculous lung was successfully removed in 1895 . Here the chest was opened and a large tuberculous abscess evacuated before infected lung tissue was methodically excised. The empty hemithorax was packed with gauze, and four weeks later the residual cavity was considerably reduced in size by a form of thoracoplasty. The patient was demonstrated 18 years later and was reported to have been seen in good health 25 years after the operation. The records are given in Macewen's own papers and are detailed in Bowman's Life of Sir William Macewen. Isolated instances of excision of tuberculous lung tissue have appeared from time to time, but it is only recently that published figures of any magnitude have appeared (Bailey et al., 1949, and Overholt et al., 1947). These records have been of considerable value in defining the scope and limitations of this form of surgery.

In our series there has been sufficient time to judge the immediate risks, but not enough to allow for a final assessment of the results. It comprises 78 cases of pulmonary resection of which 23 were undertaken "accidentally" and 55 deliberately. In every case there was definite evidence of tuberculosis in the excised specimen; healed and isolated foci were excluded, and tuberculous hilar glands were not included in the series unless they were associated with well-defined changes in the actual lung substance.

\section{DIAGNOSTIC ERRORS}

Under this heading we have collected the cases which were operated upon in ignorance of the presence of active tuberculosis, or in which there was a serious element of doubt as to whether the condition was neoplastic or of chronic inflammation. The incidence of this may be judged by the fact that there were 23 instances of pulmonary tuberculosis out of a total of 462 cases of excision undertaken by the authors for presumed bronchiectasis or neoplastic disease. This gives a percentage of 4.8 .

Bronchiectasis is the most common condition in which tuberculosis of the lung tissue is accidentally discovered. In the earlier days of chest surgery routine investigation for tubercle bacilli in the sputum was less thoroughly carried out than at the present time when the absence of bacilli is only accepted after negative results from one or more cultures or guinea-pig inoculations.

In all the cases of pulmonary excision for bronchiectasis the actual tuberculous condition was not recognized at operation and only revealed when the lobe or lung was examined by the pathologist. When lobectomy was carried out by the tourniquet technique and drainage of the chest was routinely practised, the incidence of serious pleural 
and pulmonary tuberculous complications was relatively high. A spread of disease into the upper lobe or opposite lung and pleural infection were associated in these cases. The present practice of routine dissection of the hilum and primary closure of the chest with chemotherapy has, however, led to almost complete absence of tuberculous complications, even though instances of tuberculous involvement of the excised lobe or lung have been discovered after operation.

In 15 instances tuberculosis was discovered in the resected specimen after lobectomy for bronchiectasis ; it almost always took the form of a diffuse fibro-caseous infiltration throughout the lobe. It is surprising that repeated, and in some cases exhaustive, search for tubercle bacilli in the-sputum had shown negative results.

There were three deaths occurring some time after operation and resulting from diffuse tuberculosis, usually involving an imperfectly expanded upper lobe with tuberculous pleural infection. Four other patients developed minor pulmonary infiltrations, and three of these required a later thoracoplasty to obliterate the tuberculous infected pleural space. The remaining eight patients suffered little or no apparent inconvenience and have remained fit without any evidence of tuberculosis. Twelve of the operations were lobectomies and three pneumonectomies." Women were affected more commonly than men in a proportion of $2: 1$.

The other diagnostic error is one which is often accepted with the full realization that tuberculosis may be present, but where the possibility of a growth cannot be excluded. In such an event thoracotomy will be justified, and even at operation there may be some doubt as to the nature of the mass encountered, with the result that excision is undertaken. Only in one instance out of the seven cases in this group was the patient under 45 years of age, the remainder presenting a clinical and radiological picture indistinguishable from pulmonary neoplasm. The mortality consisted of three cases which all developed a bronchial fistula with pleural infection and involvement of the opposite lung. One of the four survivors required a thoracoplasty later for tuberculous pleural infection; the remainder made satisfactory recoveries. All these subjects were men. It is probable that some pneumonectomy' specimens from people of middle age will show old, healed, or small tuberculous lesions which have not been recognized radiologically. These cases have been excluded, and in the seven cases quoted a mass of tuberculous tissue was found to correspond with the radiological shadow.
The presence of a positive tuberculous sputum may be misleading in diagnosis in the case of a suspected growth, since a positive sputum may be derived from a small active tuberculous focus or from a quiescent lesion which has actually been invaded by growth or inflammatory process. In other words, a positive sputum, while it cannot be ignored, should not be taken as evidence which would necessarily exclude a pulmonary neoplasm.

The final example in this group is the case of a young man who had violent and repeated haemoptyses without any radiological evidence of a pulmonary lesion. Bronchoscopy suggested that the blood was coming from the right side, and a further haemoptysis of two pints made surgery imperative. The right lung was excised and an unusual type of tuberculous lesion was found. The patient recovered satisfactorily.

\section{RECOGNIZED PULMONARY TUBERCULOSIS}

It is necessary to divide tuberculous lesions into two main groups consisting on the one hand of a simple or isolated tuberculous mass, the "tuberculoma," and on the other the conditions found in the ordinary forms of phthisis. This distinction is made since the problem of the tuberculoma is a simple and usually straightforward one, whereas the other is more complicated.

\section{TUBERCULOMA}

The clinical definition of the term "tuberculoma" cannot be accurately determined, since it depends on radiology and pathology rather than on clinical findings for its recognition. The lesion usually consists of a single round or oval shadow of a size varying between 1 to 2 or $3 \mathrm{~cm}$. in diameter. Tuberculous infiltration in the form of diffuse mottling is minimal or absent, though if the condition is observed over a period of years tuberculous bronchopneumonic lesions may occur and produce any of the changes that are ordinarily recognized as typical of tuberculosis. The shadow appears of even density, but on tomography it often shows irregularity, suggesting that it is made up of a conglomerate mass of smaller foci. Occasionally cavitation may be seen for a varying period, but the wall of the mass remains thick and the cavity outline though smooth is serpiginous and rarely circular. Repeated investigations for tubercle bacilli in the sputum are commonly negative, though a positive finding may be recorded on one or two occasions if examinations are made over a period of months. The condition affects young adults rather than children, and in distinc- 
tion from a primary lesion there is often only a weakly positive Mantoux reaction.

The main problem in diagnosis is to differentiate the shadow from some benign tumour, such as an adenoma, or an early carcinoma, or a fluid-containing cyst. These conditions on radiography are usually uniform in consistence without irregularities or cavitation, but it is difficult to distinguish them from tuberculomata.

A bias towards intervention is also given by an element of doubt as to the presence of a growth in some instances, and the knowledge that there is an abnormal and possibly unstable condition in the lung causes many patients to press for operation.

Fifteen cases of this type were operated on, 10 lobectomies and five segmental resections being performed. Eleven of the patients were women, four men. The lesions were most commonly situated in the right lower lobe. In all instances recovery was rapid and complete, and there has been no untoward occurrence in these patients over a period varying between one and five years.

\section{Phruisis}

The prime consideration before excision is undertaken is that other and simpler methods have been tried and failed. The second is that the residual lung tissue should be free from active and obvious disease and able to withstand the physiological and pathological strains placed on it. It is almost impossible to give accurate indications, as each problem is essentially an individual one governed by anatomical, pathological, and constitutional factors, but some general outlines can be considered under arbitrary headings.

Persistent Cavities.-Persistent cavities constitute the most common indications for excision, it being assumed that their closure has not been achieved by simple collapse measures such as artificial pneumothorax, phrenicectomy, and pneumoperitoneum, and that the cavities in question are not suitable for, or have failed to respond to, treatment by thoracoplasty. In some instances endocavity suction drainage (Monaldi) or deliberate cavernostomy may be preferred to excision owing to the less severe character of the operation or the distribution of disease in other parts of the lung.

Apart from the presence of persistent cavities the condition and extent of the disease in the lungs is the determining factor in making a selection of cases for excision, and preference will obviously be given to those in which the cavity and disease are well localized:
Cavities in the apex of the lower lobe have provided most of the material in this series, but operation has only been undertaken if collapse had not been achieved by a simpler method. Routine bronchoscopy in these cases frequently reveals stenosis or ulceration of the orifice of the first dorsal branch of the lower lobe bronchus. This has been observed in more than two-thirds of our cases and has suggested a reason for the failure of collapse measures. The value of streptomycin therapy in cases of endobronchitis is accepted, but a permanent stenosis or narrowing with persistence of the cavity is not likely to be relieved.

The decision whether to perform a lobectomy or a pneumonectomy cannot always be made until the chest has been opened. Since the cavity often lies at the upper part of the greatest fissure some degree of adhesion is inevitable, and the extent and fixity of this will influence the choice of operation. Light palpation of the upper lobe is also important, since disease that has not been recognized radiologically may be clearly felt as small shotty masses. Our experience has suggested that right lower lobe cavities have been selected for lobectomy more often than those on the left.

Cavities situated in the basal segments of the lower lobe are less common, but are anatomically more suitable for lobectomy than dorsal lobe cavities. Middle lobe cavities are theoretically suitable for lobectomy, but the poorly defined fissures make local resection problematic. Upper lobe cavities are rarely selected for excision owing to the success of the modern thoracoplasty, possibly added to, or preceded by, drainage methods ; but if the disease is strictly confined to the upper lobe, and if there is a bronchiectatic element in the lesions, upper lobectomy is possibly a more selective operation than a partial thoracoplasty.

Multiple cavitation of the distension type occasionally affords an indication that thoracoplasty will probably fail in its object. For example, a cavity almost filling the upper lobe with one in the dorsal lobe has been treated by excision.

The figures in this group consist of 25 cases, of which 19 were situated in the lower lobes, 15 on the, right. These lower lobe cavities were treated by lobectomy on 13 occasions and pneumonectomy in six instances. The remaining six patients had large cavities in upper and lower lobes and were subjected to pneumonectomy. One patient in this latter group died ten days after operation from miliary tuberculosis.

Thoracoplasty Failures. - The failure of thoracoplasty to close certain cavities is recognized, and here excision might be held to be reasonable. The 
main problem rests on the degrees of mechanical fixity of collapsed lung to the chest wall. Our experiences with " revision" or korrectur thoracoplasty have shown how difficult in some cases it may be to free or mobilize a lung adequately without injuring its substance. This same problem applies in excision where regenerated ribs and adherence of the lung may make exposure and dissection of the upper lobe very difficult. Consequently the operation is one of severity, virtually consisting of a revision thoracoplasty followed by excision. Parietal freeing is invariably more arduous than the mediastinal dissection.

Three patients were operated on in this category; two were right upper lobectomies, the other a left pneumonectomy. The immediate result was satisfactory, but in all three cases the appearance of a late bronchial fistula (four to six weeks after operation) was followed by tuberculous bronchopneumonia in the opposite lung. This led to death some weeks later in all instances.

In spite of these misadventures it is not felt that excision should be excluded from this type of case, but that the difficulties should be fully appreciated and consideration be given to other forms of treatment such as cavernostomy before deciding upon resection.

Bronchial Stricture.-A severe bronchial stenosis as a result of tuberculous endobronchitis results in distal bronchiectatic changes which cannot be treated by any method other than excision. If there is little secretion the condition is not necessarily serious, but if there is abundant sputum the outlook without operation is hazardous. The selection of cases is, in this event, largely dominated by the condition of the opposite lung, which is particularly liable to aspiration infection as long as copious sputum is being expectorated. The lung beyond the stricture is collapsed and shrunk and consists of a mass of carnified and caseous tissue surrounding bronchiectatic areas which produce a variable quantity of secretion.

On the other hand a complete stricture retains secretions and produces a lung which is a necrotic bag of pus. Cases are also unfortunately not unknown in which, as the result of an ill-selected artificial pneumothorax, the lung has remained completely collapsed and the pleural cavity has become infected by tuberculosis. In such excision of both pleura and lung should be considered.

In this type of case the surgical problems are extensive. The patient is toxic and debilitated as a result of prolonged suppuration, adhesion of the damaged lung to the chest wall is often extreme, and the affected bronchus is acutely inflamed and the site of tuberculous infection. These factors should not unduly discourage active treatment, as successful surgery does give most gratifying results.

Nine patients with this type of lesion were operated on with success in eight instances. The fatal case developed a late bronchial fistula with pleural infection and died some time later from a spread of the tuberculous infection in the remaining lung.

"Destroyed Lung."-Excision in the presence of acute or gross disease is problematic, but there is an occasional instance in which pneumonectomy seems justified. It is practically a measure of despair undertaken with the almost certain knowledge that the prognosis would otherwise be hopeless. The disease must be virtually unilateral and not amenable to collapse measures. Good results cannot always be expected, though the five patients treated under this heading have survived the operation.

In one patient excision had been agreed on for a lower lobe cavity, but while awaiting operation there was a sudden spread of disease into the upper lobe. Pneumonectomy was performed in the presence of actively spreading caseous disease and there was satisfactory recovery, though a silent spread occurred six weeks later in the opposite base. The other instances were those of severe and spreading disease in one lung with the development of several tension cavities. Here again pneumonectomy was successful, but it is realized that good long-term results have not yet been proved.

TABLE I

ANalysis of Series

\begin{tabular}{|c|c|c|c|}
\hline Type of Case & & $\begin{array}{l}\text { No. of } \\
\text { Cases }\end{array}$ & $\begin{array}{l}\text { Deaths (within } \\
\text { Six Months } \\
\text { of Operation) }\end{array}$ \\
\hline 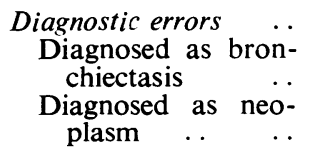 & $\begin{array}{r}15 \\
8\end{array}$ & 23 & 3 \\
\hline Tuberculoma ... & 15 & 15 & 0 \\
\hline $\begin{array}{l}\text { Phthisis . . . } \\
\text { Persistent cavitation } \\
\text { Thorocoplasty failure } \\
\text { Bronchostenosis .. } \\
\text { "Destroyed " lung }\end{array}$ & $\begin{array}{r}23 \\
3 \\
9 \\
5\end{array}$ & 40 & $\begin{array}{l}1 \\
3 \\
1 \\
0\end{array}$ \\
\hline Totals & & 78 & 11 \\
\hline
\end{tabular}


TABLE II

TYPE OF OPERATION

\begin{tabular}{|c|c|c|c|c|c|c|c|c|}
\hline & 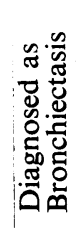 & 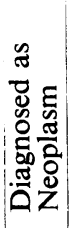 & 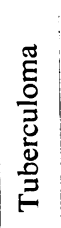 & 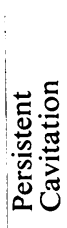 & 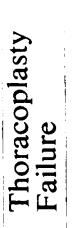 & 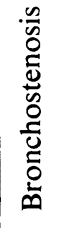 & 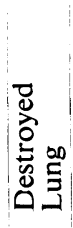 & 吾 \\
\hline Pneumonectomy & 3 & 7 & - & 10 & 1 & 7 & 5 & 33 \\
\hline Lobectomy & 12 & 1 & 10 & 13 & 2 & 2 & - & 40 \\
\hline $\begin{array}{c}\text { Segmental resec- } \\
\text { tion .. }\end{array}$ & - & - & 5 & - & - & - & - & \\
\hline
\end{tabular}

\section{TECHNICAL CONSIDERATIONS}

The dangers of pneumonectomy or lobectomy in tuberculosis can be divided into those of the operation itself and those of later exacerbation or spread of the tuberculous process. The value of streptomycin has been emphasized in other published series (Bailey et al., 1949, and Moore et al., 1949), but this drug was only available for about one-third of our patients. The early cases were undertaken without this "umbrella," but apparently with little ill effect.

The problems of anaesthesia are even more complex than with suppurative conditions or growth, since aspiration of tuberculous material into unaffected lung tissue in the unconscious patient is fraught with considerable danger and may easily lead to spread of the disease. We have used the "head-down-face-down" position described by Parry Brown (1948) for all our lobectomies and pneumonectomies for the last six or seven years, and have found it particularly valuable in the tuberculous patient. This differs in principle from the method recorded by Overholt and Wilson (1946), who use a posterior approach but aim at retaining secretion in the lung to be excised. We aim at continuous drainage while protecting the remainder of the lung fields. There is no necessity to discuss here operative techn:que, which consists of the standard dissection of the individual hilar elements, but special points applicable to tuberculous cases may be briefly stated.

At operation it may be found that many of the adhesions are highly vascular, and if there is an extensive area of pleural adhesion an extrapleural dissection will be required, even though it involves the whole of the parietal pleura. The operation may end up by being a pleurectomy as well as a pneumonectomy. This inevitably entails bleeding and oozing, which is sometimes difficult to control completely without such haemostatic agents as fibrin foam or alginates or diathermy coagulation. Damage to the lung is often difficult to avoid, since infiltrated tissue may actually crack or break. The use of lung-holding forceps (such as Duval's) should be avoided altogether or reduced to a minimum.

Where there is additional suppuration, as with a.bronchiectatic lobe, the degree of shock and bleeding may be severe. The fissures are usually obliterated; this may preclude lobectomy, since the plane cannot be established without opening extensively into tuberculous tissue. The hilar elements may not be unduly obscured, but in some instances glandular masses and infiltration make this part of the operation difficult and tedious.

Closure of the bronchus stump is one of the most important features of the operation, since it would appear that the fate of the patient largely depends on the integrity of the healing. In this connexion several points have to be observed. The bronchus is cut off as close as possible to the parent stem so as to avoid leaving any stump which might harbour pus. The bronchus is sutured by interrupted linen sutures embracing about $2 \mathrm{~mm}$. of each side and placed 1 to $2 \mathrm{~mm}$. apart. The closed stump is then covered by a pedicled intercostal muscle graft which has been previously prepared. Pleural flaps may be used in addition, but they are not always available if extensive extrapleural excision has been carried out. The necessity for detailed and meticulous care in this stage is shown by the fact that we have found that tuberculous infiltration of the bronchial wall was present at the point of section in nearly every case.

The immediate operative mortality is not excessive if all possible precautions have been taken in the selection and preparation of patients and in the technical aspects of the actual operation. The dangers arise at a later stage and are connected, as in nearly all pulmonary work, with bronchial fistula and pleural infection.

The effect of a bronchial fistula may be disastrous and can be illustrated by the fact that it was present in 10 out of 11 fatal cases and directly contributed to contralateral spread. Over the whole series 14 fistulae were diagnosed, eight occurring in the "diagnostic error" group ; the remaining six fistulae developed much later than usual in the post-operative course (between four and six weeks) with four of them contributing 
to the death of a patient. The longest proven interval between operation and fistula formation was 14 weeks, though in one case an opening between a residual pneumonectomy dead space and the bronchus developed six to nine months later.

The spread of the tuberculous process into residual parts of the lung might be expected to occur within a short time of operation, but apart from those cases in which there was a proved bronchial fistula there were only three instances; one cleared up quickly under combined penicillin and streptomycin therapy ; the others, one already instanced under "destroyed lung" have caused the patient little inconvenience but are clearly of serious prognostic signification.

The dead space left by removal of part or the whole of a lung constitutes a special problem in tuberculosis, since traction on remaining tissue may adversely affect quiescent areas of disease. Also a dead space may well become a site of a tuberculous infection at a later date, and this has occurred in two instances. Obliteration of the space is desirable, and much can be obtained by the use of phrenicectomy and pneumoperitoneum. Paralysis of the diaphragm alone is often adequate after a lower lobectomy. When this effect is added to by pneumoperitoneum it can be used after upper lobe excisions, since the residual lower lobe is elevated towards the apex where it can expand and fully fill the pleural space. After this has occurred the pneumoperitoneum can be abandoned. This combined procedure is also a great help after pneumonectomy but does not obliterate the space comp'etely. It has been recognized and should probably be accepted that thoracoplasty should follow pneumonectomy for tuberculosis, but in this series the secondary operation has only bzen used on six occasions. Our hesitation in performing thoracoplasty is based more on humanitarian than on scientific reasons. It is difficult to be sure that the patient's morale will not be affected by being subjected to a thoracoplasty within a short time of pneumonectomy. In some cases an upper four- or five-rib thoracoplasty is sufficient to close the residual space if the diaphragm has been markedly raised: more usually a two-stage seven- or eight-rib operation is required. If this is to be done it should be undertaken without much delay before the chest wall becomes too rigid or the ribs structurally altered. In those cases in which we have withheld thoracoplasty the space obliterated quickly with fibrin and clot in some instances, and in others, where there was little pleural reaction, a pneumothorax has been maintained with refills over four or six weeks up to a period of six months or a year. It was in two of these cases that a tuberculous effusion developed at a later date but did not produce any apparent ill effect.

The use of blood transfusions and chemotherapy has contributed greatly to the success of the operations; blood transfusions have been given routinely during the operation, taking care that the circulation does not become overburdened in the case of pneumonectomy, where an arbitrary limit of two pints of blood should be adhered to unless there has been any extensive haemorrhage. Penicillin has been used as a "cover" in the immediate operative and post-operative phases and has been used locally round the bronchus stump and in the pleural cavity.

Our experience with streptomycin has been limited, as it has only been used in about onethird of the "deliberate" cases. It is an interesting point of comparison to find that the mortality and complications did not differ appreciably in those done with and without streptomycin (Table III). There is little doubt, however, as to

TABLE III

USE OF STREPTOMYCIN

\begin{tabular}{|c|c|c|c|c|}
\hline Type of Case & $\begin{array}{l}\text { Used } \\
\text { (No. of } \\
\text { Cases) }\end{array}$ & Deaths & $\begin{array}{l}\text { Not } \\
\text { Used } \\
\text { (No. of } \\
\text { Cases) }\end{array}$ & Deaths \\
\hline $\begin{array}{l}\text { Tuberculoma } \\
\text { Persistent cavities } \\
\text { Thoracoplasty failure } \\
\text { Bronchostenosis } \\
\text { Destroyed lung } \quad \text {. }\end{array}$ & $\begin{array}{l}4 \\
7 \\
1 \\
4 \\
5\end{array}$ & $\begin{array}{l}1 \\
1\end{array}$ & $\begin{array}{r}11 \\
16 \\
2 \\
5 \\
0\end{array}$ & $\begin{array}{l}1 \\
2\end{array}$ \\
\hline & 21 & 2 & 34 & 3 \\
\hline
\end{tabular}

the efficiency and value of this antibiotic, which may well afford greater latitude and permit even more local operations, which to date have not been undertaken for fear of direct damage to tuberculous tissue.

The end-results in this series cannot be formulated as a long-term policy. All that can be said is that surviving patients have been followed up for at least six months and some up to three years, and these patients have shown no further evidence of tuberculous involvement of the lung beyond those instances already mentioned. 


\section{SUMMARY}

A series of 78 cases is recorded in which lobectomy or pneumonectomy in the presence of pulmonary tuberculosis was undertaken.

Twenty-three of the resections were negotiated without realizing that tuberculous infection was present: some of these cases date back 10 years. Six of these patients died as a consequence of the operation.

Deliberate excision for a known tuberculous lesion was underiaken in 55 patients. Fifteen of these excisions were for tuberculoma, with no fatalities and satisfactory results. The remaining 40 resections were undertaken for pulmonary and bronchial lesions. Five patients died in this group.

The indications for operation and selection of cases are discussed, and some technical aspects of the operation are given.

\section{REFERENCES}

Alexander, J. (1945). J. thorac. Surg., 14, 47.

Bailey, C. P. (1945). Diagnosis and Manasement of the Thoracic Patient. Philadelphia: Lippincott.

Bailey, C. P. (1947). J. thorac. Surg., 16, 328.

Bailey, C. P., Glover, R. P., and O'Neill, T. J. F. (1949). J. thorac. Surg., 18, 36.

Brown, A. I. Parry (1948). Thorax, 3, 161.

Chamberlain, J. M. (1945). J. thorac. Surg., 14, 32

Churchill, E. D., and Klopstock, R. (1943). Ann. Surg., 117,641

Dollev. F. S., and Jones, J. C. (1941) . J. thorac. Surg. $10,102$.

Moore, J. A., et al. (1949). J. thorac. Surg., 18, 45.

Overholt, R. H., Langer, L., Szypulski, J. T., and Wilson, N. J. (1946). J. thorac. Surg., 15, 384.

Overholt, R. H., et al. (1947). Amer. Rev. Tuber:, 55, 198.

Sellors, T. H., Thompson, V. C., and Qvist, G. (1944). Lancet, 2, 101.

Sweet, R. H. (1945). J. thorac. Surg., 15, 373.

Thornton, T. F., and Adams, W. F. (1942). Sirrg. Ginec. Obstet., 75 (Int. Abstr. Surv.), 312. 


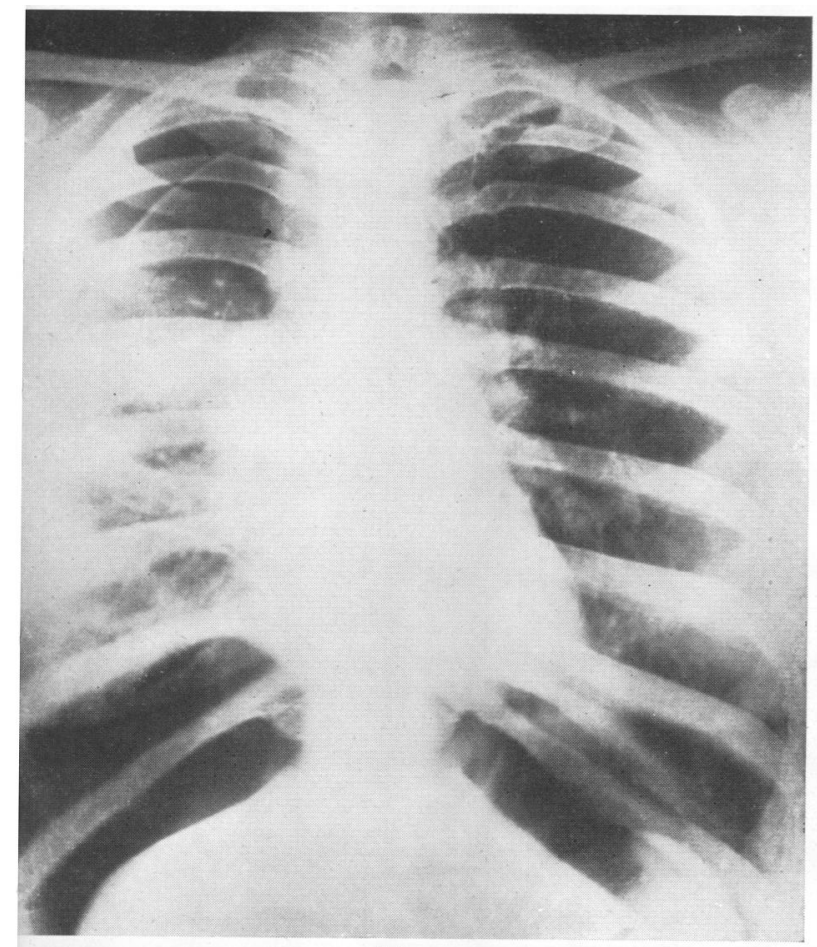

(a)

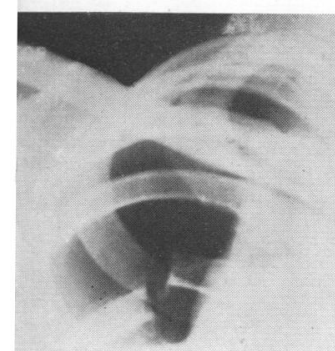

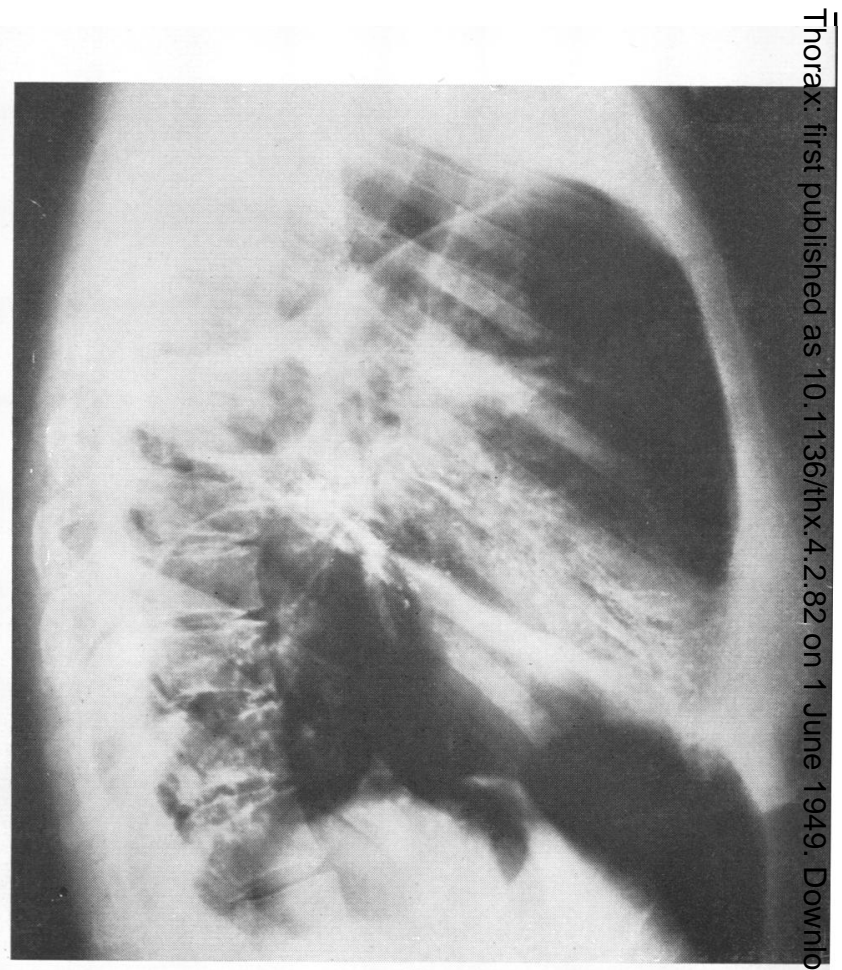

(b)

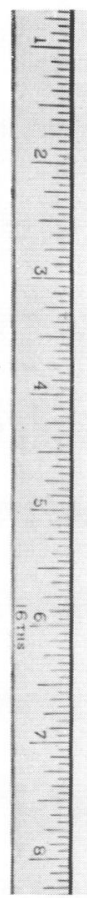

(c)

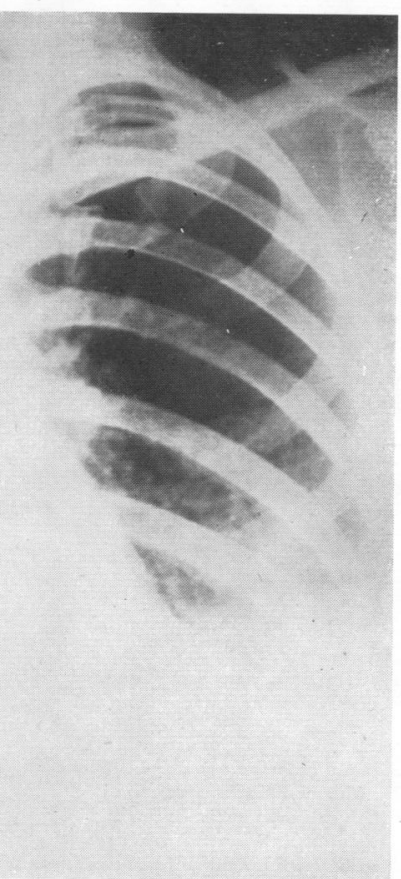

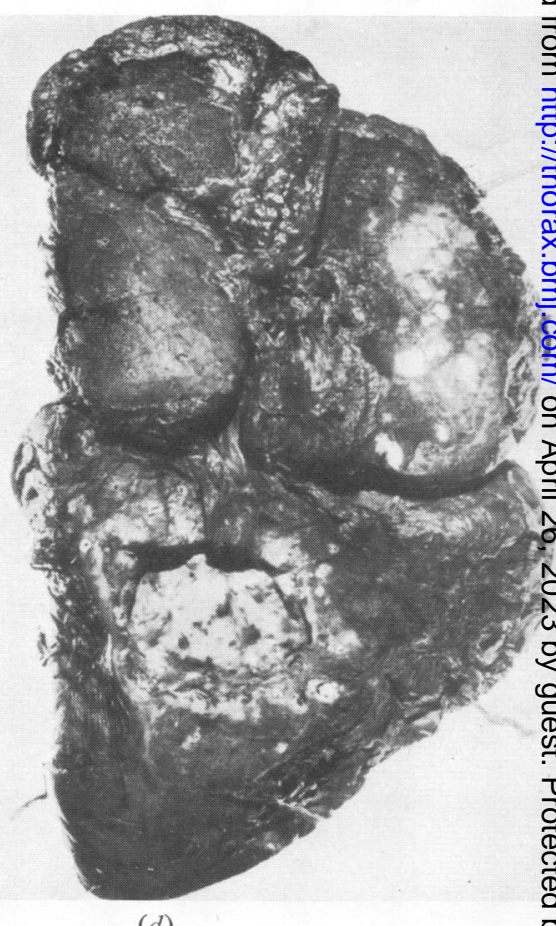

$(d)$

Plate 1.- $(a)$ and $(b)$ Extensive tuberculous disease with cavitation on right side. Failure of right artificial pneumothorax and 8 marked improvement after phrenicectomy and pneumoperitoneum. (c) Radiograph one year after pneumonectomy shows parta obliteration of dead space, but pleural effusion later develored on other side. Patient improved after being kept under observatio. for further six months. (d) Specimen. 


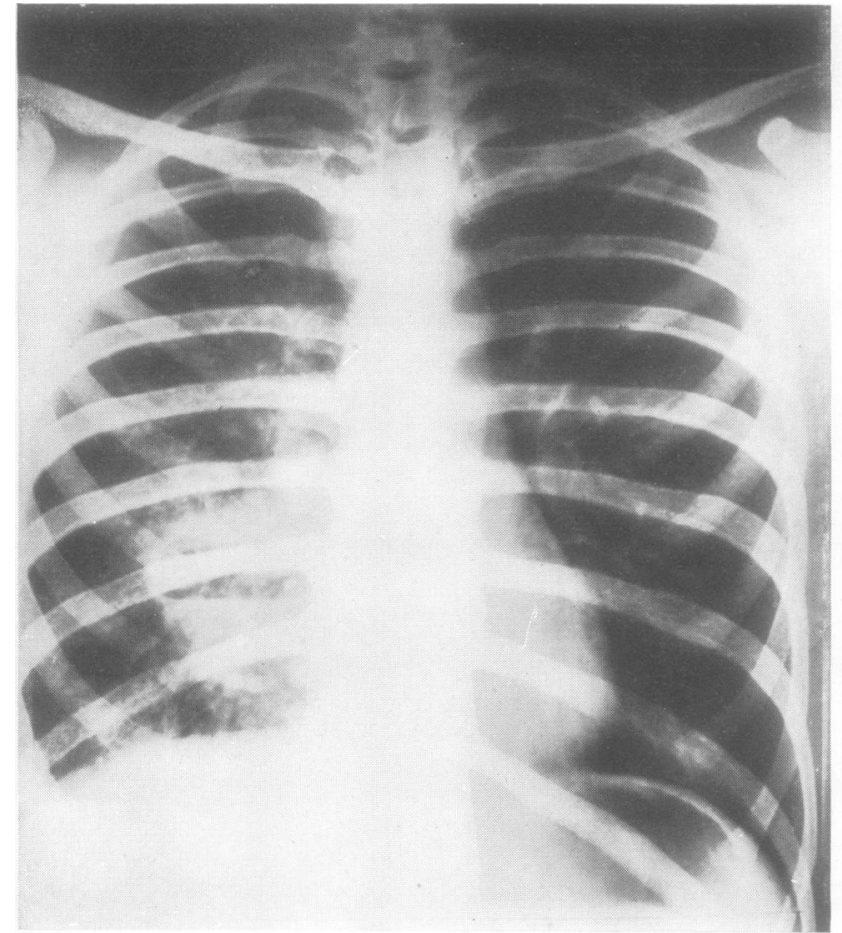

(a)

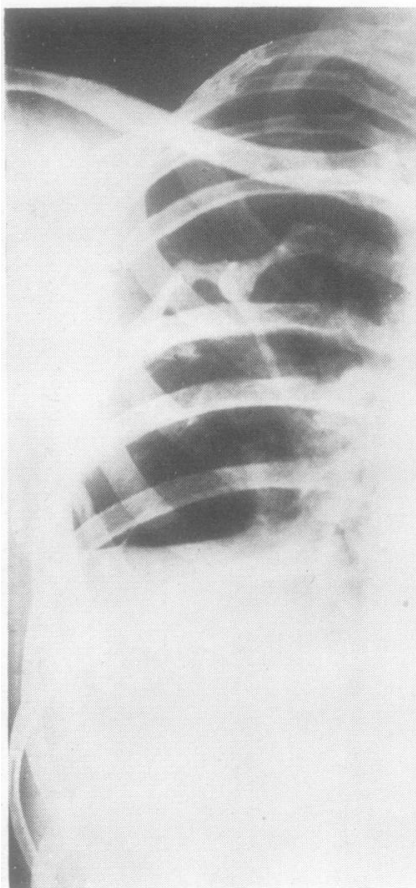

(c)

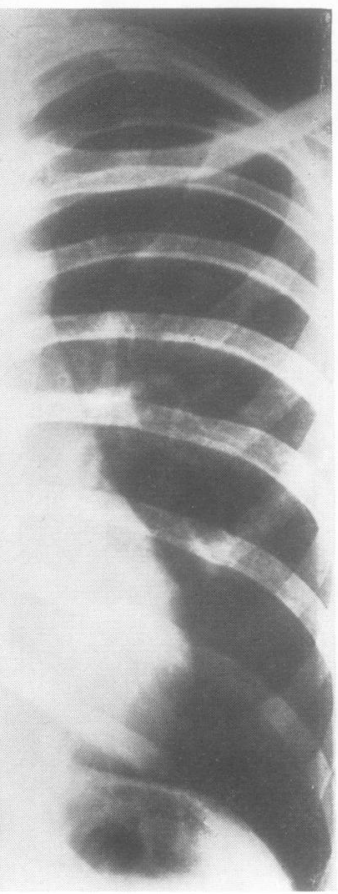

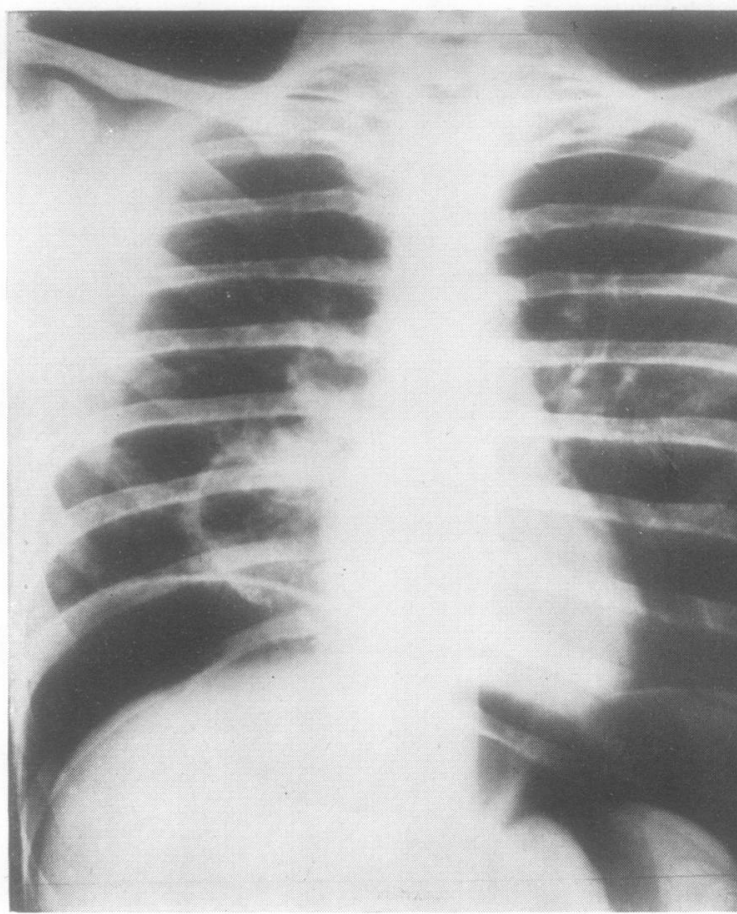

(b)

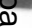

$\stackrel{2}{\stackrel{2}{10}}$

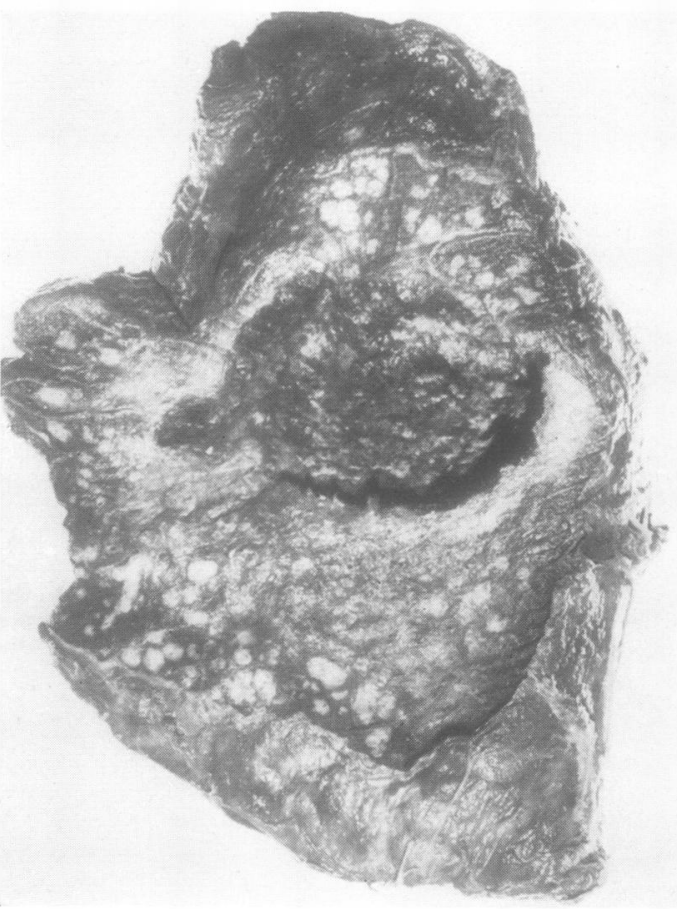

(d)

Plate 2.- $(a)$ and $(b)$. Lower zone infiltration with large cavity and fluid level at right base. This did not respond to collapse measơ (Artificial pneumothorax failed; phrenicectomy and pneumoperitoneum ineffective.) (c) Appearance three years after right lewer lobectomy showing permanently high diaphragm. Note regenerated bone leading towards hilum. This represents position of intercosta! muscle graft. $(d)$ Specimen showing extensively caseous areas in addition to cavitation. 


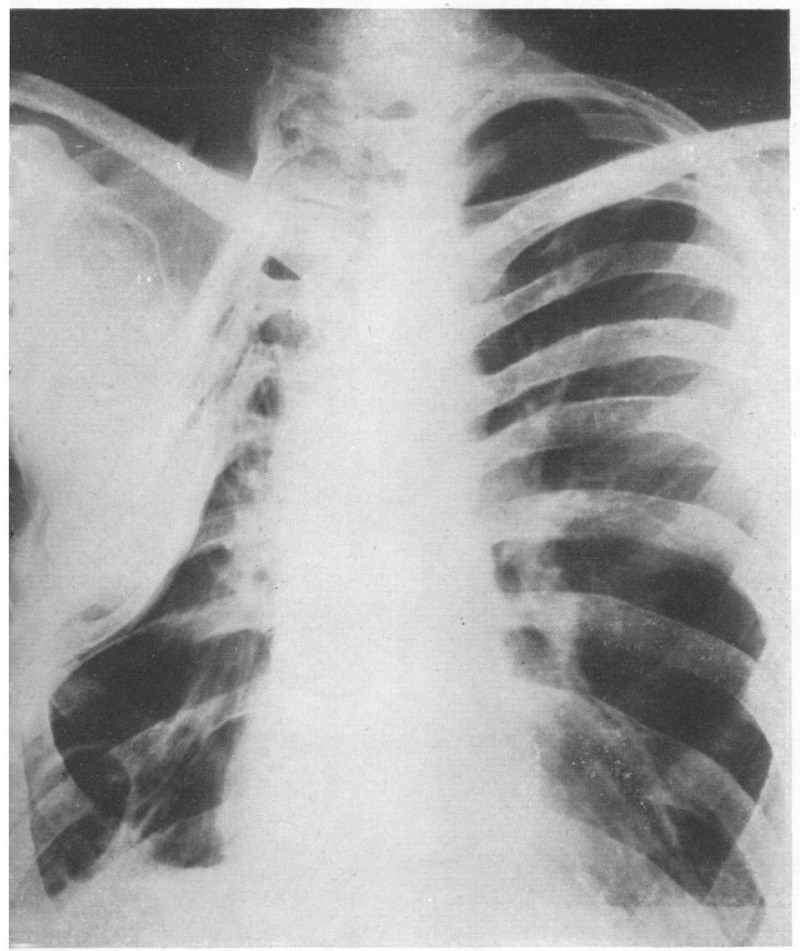

(a)

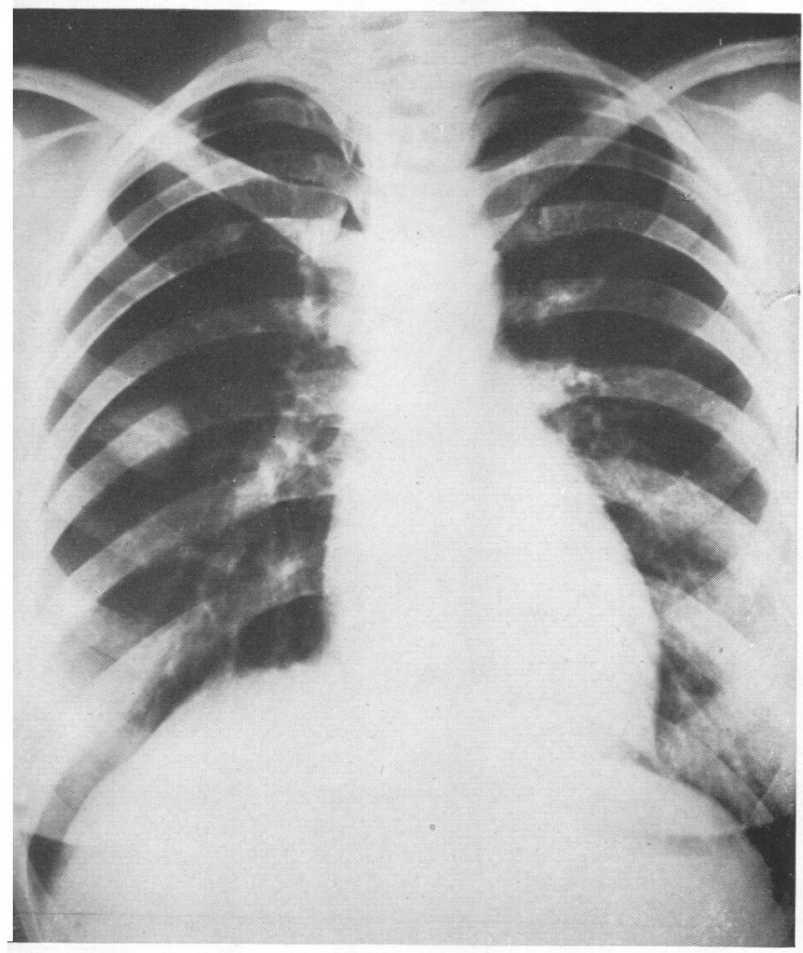

(c)
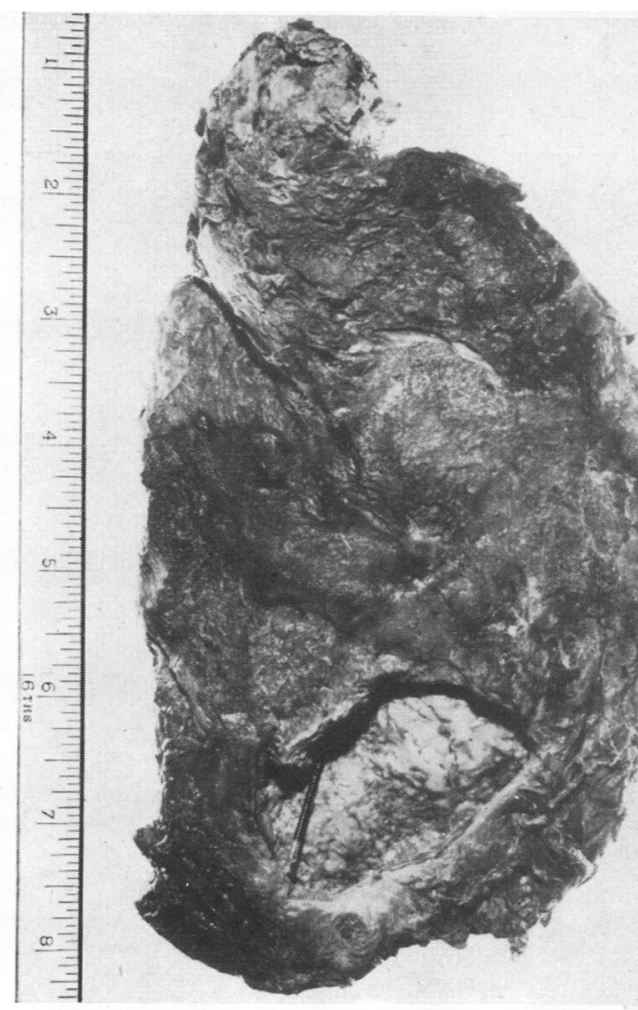

(b)

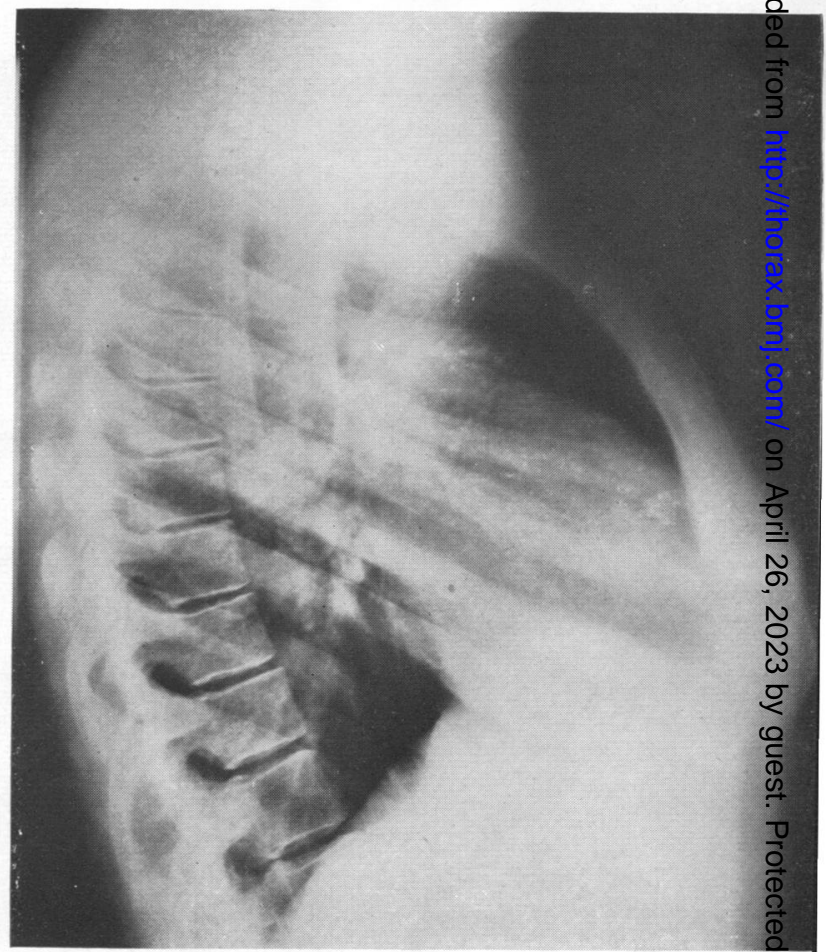

(d)

'LATE 3.-(a) Left basal cavitation following thoracoplasty four years previously. Death occurred some weeks after operation from tuberculous involvement of opposite lung consequent on a bronchial fistula. (b) Pneumonectomy specimen showing unhe cavities under thoracoplasty as well as large cavity at base of lung. $(c)$ and $(d)$ Tuberculoma at apex of right lower lobe. Treaged satisfactorily by segmental resection. 


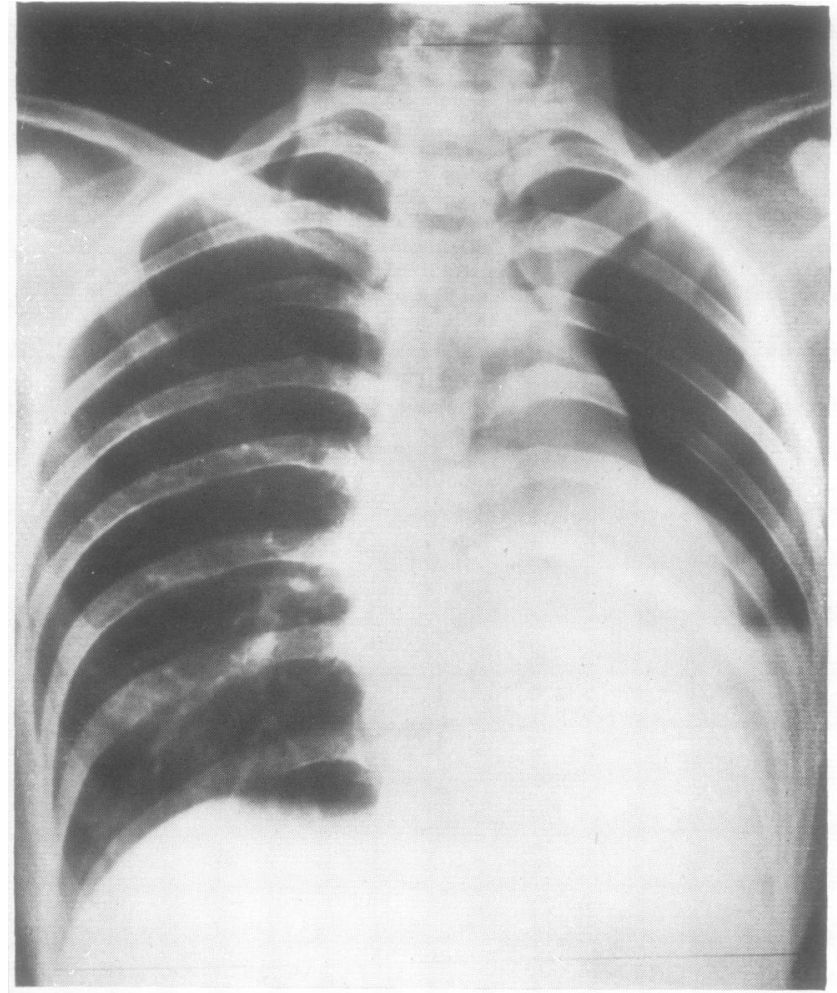

(a)

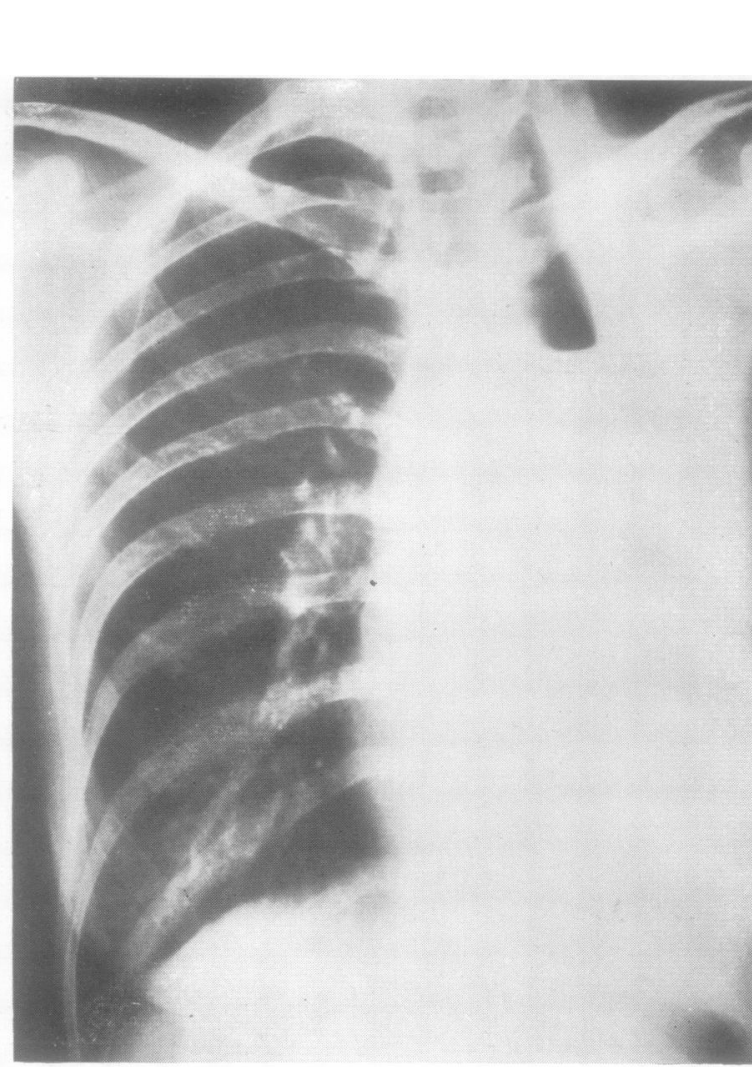

(b)

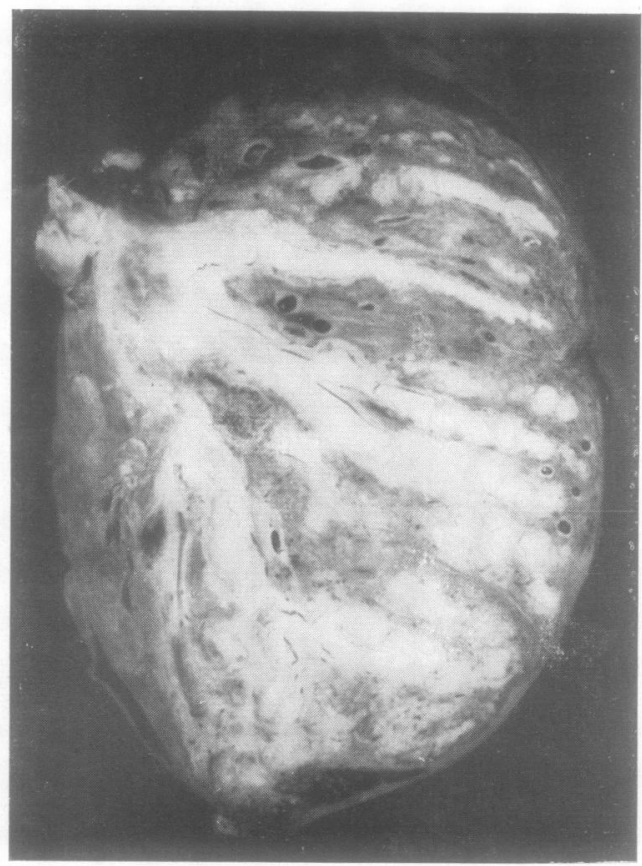

(c)

PLATE 4.-(a) Right tuberculous bronchostenosis. Permanent collapse and bronchiectatic changes had followed pneumothorax treatnent six months before. (b) Appearance after pneumonectomy with subsequent limited thoracoplasty. (c) Specimen showing marked tukerculous bronchiectasis. 

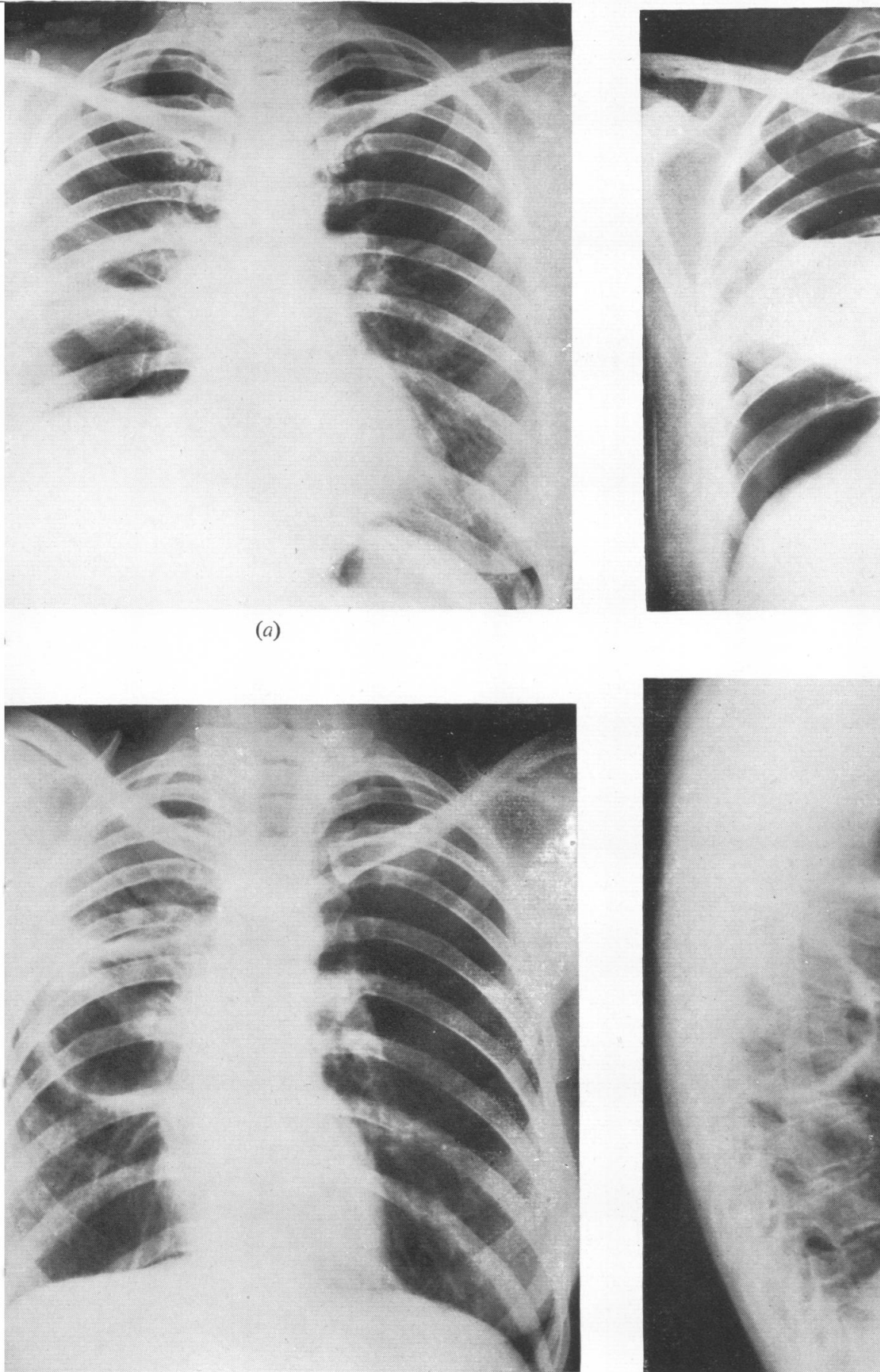

(c)

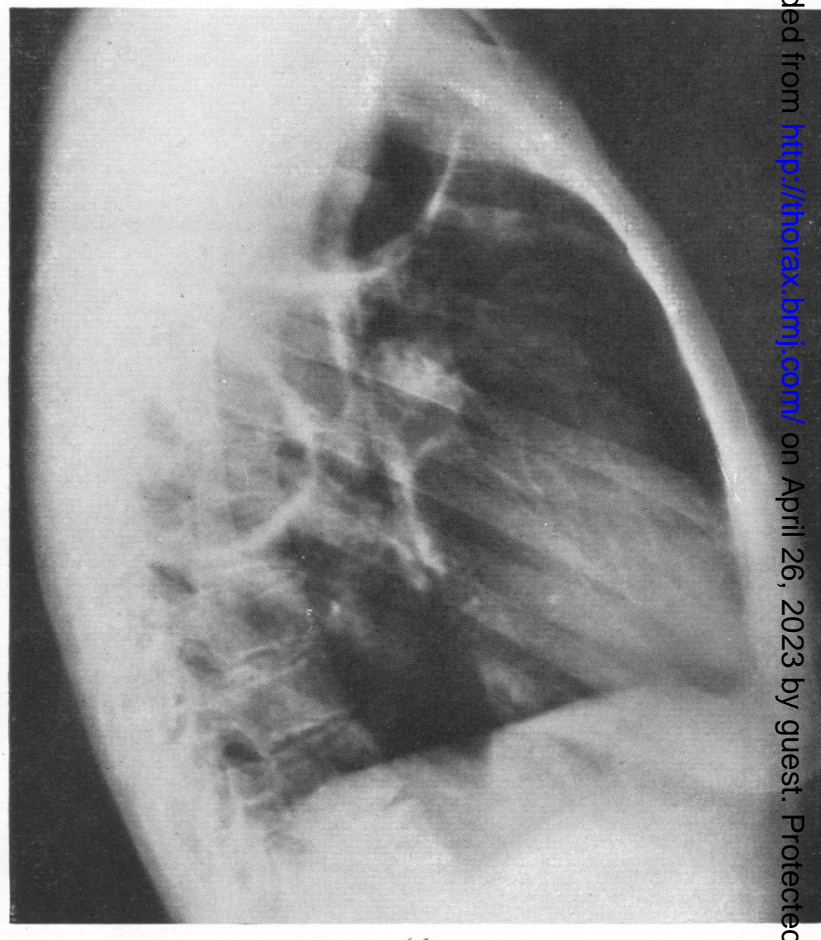

(d)

Plate 5.- (a) Cavity at apex of right lower lobe. This failed to respond to phrenicectomy and pneumoperitoneum. (b) Radiograpph after right lower lobectomy showing small amount of residual effusion three weeks after. (c) and (d) Giant cavity in right upger lobe and apex of lower. Pneumonectomy performed. Patient died ten days later from miliary tuberculosis. 


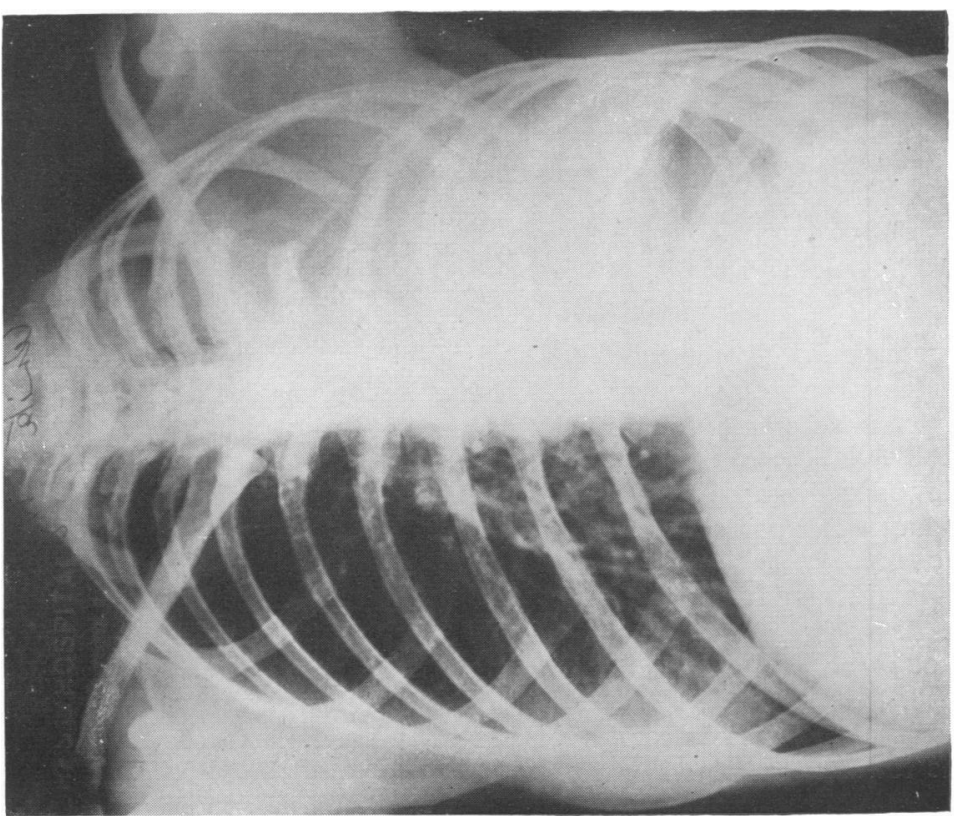

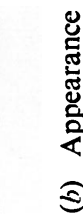

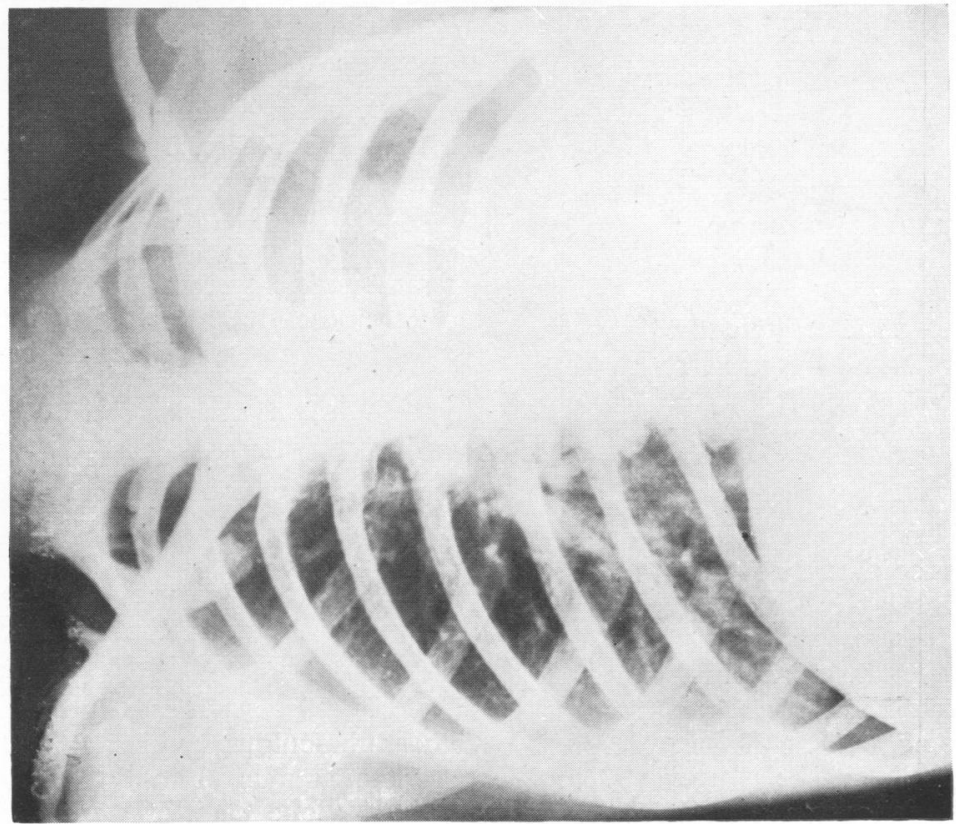

豆

e

芩

홇릴

$\gtrsim$

중 응

는

훙

엉 